\title{
Analysis of Matrix Effect of Urine Quality Control Materials in Urine Chemistry Tests
}

\author{
Chang-Ho Jeon and Sang-Gyung Kim \\ Department of Laboratory Medicine, School of Medicine, Daegu Catholic University, Daegu, Korea
}

\section{Corresponding author:}

Chang-Ho Jeon

Department of Laboratory Medicine,

Daegu Catholic University Medical

Center, School of Medicine, Catholic

University of Daegu, 33 Duryugongwon-

ro 17-gil, Nam-gu, Daegu 42472, Korea

Tel +82-53-650-4144

Fax +82-53-653-8672

E-mail chjeon@cu.ac.kr

Received: July 10, 2020

Revised: September 3, 2020

Accepted: September 11, 2020

This is an Open Access article distributed under the terms of the Creative Commons Attribution Non-Commercial License (http://creativecommons.org/licenses/ by-nc/4.0) which permits unrestricted non-commercial use, distribution, and reproduction in any medium, provided the original work is properly cited.
Background: The National External Quality Assessment Service on urinalysis in Korea has used control materials manufactured by YD (YD Diagnostics, Korea). These materials are composed of phosphate-buffered saline mixed with real materials or chemical reagents. Therefore, matrix effects could influence the urine analysis results.

Methods: We obtained five kinds of control materials from YD Diagnostics, Aution Check Plus (Arkray Inc., Japan), Liquichek Urinalysis Control (BioRad Inc., USA), UroColor Control (Standard Diagnostics, Korea), and UCControl (Sysmex Co., Japan), and prepared normal and abnormal human urine samples for testing. As test devices, we selected the following six instruments: Super+ (YD Diagnostics), Aution Max AX-4030 (Arkray Inc.), UroMeter 720 Pro (Standard Diagnostics), Clinitek Adventus (Siemens Healthcare, Germany), URISYS 2400 (Roche Diagnostics, Germany), and UC1000 (Sysmex Co.) based on the database of the Korean Association of External Quality Assessment Service. We performed our analysis using the five control materials, two human urine samples, and six instruments.

Results: Matrix effects were found in all control materials: Aution Check ( $\mathrm{pH}$ in URISYS, specific gravity [SG] in Aution Max), Liquichek (urobilinogen in Aution Max, SG in UC1000), UroColor (bilirubin and SG in Aution Max, pH and SG in UC1000), and UC-Control (bilirubin and SG in UroMeter, bilirubin in UC1000, and ketone in Clinitek). YD controls also presented matrix effects: blood and urobilinogen in Aution Max, glucose in Super+, SG in UC1000, and $\mathrm{pH}$ in URISYS.

Conclusions: Since all control materials showed matrix effects, external quality assessment should be evaluated by the results of the peer group rather than by those of the manufacturer.

(Lab Med Qual Assur 2020;42:200-210)

Key Words Urine, Quality control, Urinalysis

\section{서론}

현재 요화학검사의 신빙도조사는 국내 시약회사에서 액상 으로 제조되는 정도관리물질을 사용하고 있다[1,2]. 이 물질은 phosphate buffered saline에 요화학검사를 위한 첨가물을 혼 합하여 정도관리물질로 사용하고 있다. 첨가물에는 albumin, 포
도당, 혈색소, acetoacetic acid 등 실제 물질도 있지만, 백혈구, 적혈구, bilirubin, urobilinogen, nitrite 등은 실제 물질이 아니 라 동일한 반응을 일으키는 화학물질을 첨가하여 정도관리 검체로 사용하고 있다.

따라서 요화학검사 신빙도조사사업에서는 정도관리 검체에 따 른 기질효과가 나타날 가능성이 있으며 아직 이에 대한 연구가 진 
행된 것은 없다. 최근 국내 의료환경이 변화되어 각 병원에서 시행 하고 있는 신빙도조사 결과에 대해 높은 정확성이 요구되고 있다. 기질효과에 의한 요화학검사의 결과 오류는 신빙도조사 결과에 부 정적인 영향을 끼치게 되므로 기질효과 존재 여부에 대한 체계적
인 연구가 필요한 실정이다.

본 연구에서는 현재 사용되고 있는 요화학 정도관리 검체와다른 제조 사에서 생산되는 요화학 정도관리 검체를 사용하여 정도관리 검체에 따 라요화학검사 시약에서 반응할 수 있는 기질효과를 분석해 보고자 한다.

Table 1. Interpretation guidelines for urine sticks of different manufacturers

\begin{tabular}{|c|c|c|c|c|c|c|}
\hline \multirow{2}{*}{ Test } & \multicolumn{6}{|c|}{ Company } \\
\hline & YD & SD & Roche & Siemens & Sysmex & Arkray \\
\hline \multicolumn{7}{|l|}{ Blood } \\
\hline Unit & $\mathrm{RBC} / \mu \mathrm{L}$ & $\mathrm{RBC} / \mu \mathrm{L}$ & $\mathrm{RBC} / \mu \mathrm{L}$ & $\mathrm{RBC} / \mu \mathrm{L}$ & $\mathrm{mg} / \mathrm{dL}$ & $\mathrm{mg} / \mathrm{dL}$ \\
\hline \multicolumn{7}{|l|}{ Grade } \\
\hline- & Neg & Neg & Neg & Neg & Neg & Neg \\
\hline+- & 5 & - & 10 & Trace & 0.03 & 0.03 \\
\hline $1+$ & 10 & 10 & 25 & Small & 0.08 & $0.06-0.1$ \\
\hline $2+$ & 50 & 50 & 50 & Moderate & 0.15 & $0.2-0.5$ \\
\hline $3+$ & 250 & 250 & 150 & Large & 0.75 & $\geq 1.0$ \\
\hline $4+$ & NA & NA & 250 & NA & NA & NA \\
\hline \multicolumn{7}{|c|}{ Leukocyte } \\
\hline Unit & $\mathrm{WBC} / \mu \mathrm{L}$ & $\mathrm{WBC} / \mu \mathrm{L}$ & $\mathrm{WBC} / \mu \mathrm{L}$ & $\mathrm{WBC} / \mu \mathrm{L}$ & $\mathrm{WBC} / \mu \mathrm{L}$ & $\mathrm{WBC} / \mu \mathrm{L}$ \\
\hline \multicolumn{7}{|l|}{ Grade } \\
\hline- & Neg & $\mathrm{Neg}$ & Neg & Neg & Neg & Neg \\
\hline+- & NA & NA & NA & Trace & NA & NA \\
\hline $1+$ & 25 & 25 & 25 & Small & 25 & 25 \\
\hline $2+$ & 75 & 75 & 100 & Moderate & 75 & 75 \\
\hline $3+$ & 500 & 500 & 500 & Large & 500 & 250 \\
\hline $4+$ & NA & NA & NA & NA & NA & 500 \\
\hline \multicolumn{7}{|l|}{ Nitrite } \\
\hline Unit & $\mathrm{mg} / \mathrm{dL}$ & $\mathrm{mg} / \mathrm{dL}$ & $\mathrm{mg} / \mathrm{dL}$ & $\mathrm{mg} / \mathrm{dL}$ & $\mathrm{mg} / \mathrm{dL}$ & $\mathrm{mg} / \mathrm{dL}$ \\
\hline \multicolumn{7}{|l|}{ Grade } \\
\hline- & Neg & Neg & Neg & Neg & Neg & $\mathrm{Neg}$ \\
\hline $1+$ & $\mathrm{P}$ & $>0.5$ & $\mathrm{P}$ & $\mathrm{P}$ & 0.1 & 0.08 \\
\hline $2+$ & NA & NA & NA & NA & 0.3 & 0.5 \\
\hline \multicolumn{7}{|l|}{ Protein } \\
\hline Unit & $\mathrm{mg} / \mathrm{dL}$ & $\mathrm{mg} / \mathrm{dL}$ & $\mathrm{mg} / \mathrm{dL}$ & $\mathrm{mg} / \mathrm{dL}$ & $\mathrm{mg} / \mathrm{dL}$ & $\mathrm{mg} / \mathrm{dL}$ \\
\hline \multicolumn{7}{|l|}{ Grade } \\
\hline- & Neg & Neg & Neg & Neg & Neg & Neg \\
\hline+- & 10 & 10 & 25 & Trace & 15 & $10-20$ \\
\hline $1+$ & 30 & 30 & 75 & 30 & 30 & $30-70$ \\
\hline $2+$ & 100 & 100 & 150 & 100 & 100 & $100-200$ \\
\hline $3+$ & 300 & 300 & 500 & $>300$ & 300 & $300-600$ \\
\hline $4+$ & 1,000 & 1,000 & NA & 2,000 & 1,000 & $>600$ \\
\hline
\end{tabular}


Table 1. Continued

\begin{tabular}{|c|c|c|c|c|c|c|}
\hline \multirow{2}{*}{ Test } & \multicolumn{6}{|c|}{ Company } \\
\hline & YD & SD & Roche & Siemens & Sysmex & Arkray \\
\hline \multicolumn{7}{|l|}{ Glucose } \\
\hline Unit & $\mathrm{mg} / \mathrm{dL}$ & $\mathrm{mg} / \mathrm{dL}$ & $\mathrm{mg} / \mathrm{dL}$ & $\mathrm{mg} / \mathrm{dL}$ & $\mathrm{mg} / \mathrm{dL}$ & $\mathrm{mg} / \mathrm{dL}$ \\
\hline \multicolumn{7}{|l|}{ Grade } \\
\hline- & Neg & Neg & Neg & $\mathrm{Neg}$ & Neg & Neg \\
\hline+- & 100 & 100 & 50 & NA & 50 & $30-50$ \\
\hline $1+$ & 250 & 250 & 100 & 100 & 100 & $70-100$ \\
\hline $2+$ & 500 & 500 & 300 & 250 & 250 & $150-200$ \\
\hline $3+$ & 1,000 & 1,000 & 1,000 & 500 & 500 & $300-500$ \\
\hline $4+$ & $<2,000$ & 2,000 & NA & $<1,000$ & $<2,000$ & $<1,000$ \\
\hline \multicolumn{7}{|l|}{ Ketone } \\
\hline Unit & $\mathrm{mg} / \mathrm{dL}$ & $\mathrm{mg} / \mathrm{dL}$ & $\mathrm{mg} / \mathrm{dL}$ & $\mathrm{mg} / \mathrm{dL}$ & $\mathrm{mg} / \mathrm{dL}$ & $\mathrm{mg} / \mathrm{dL}$ \\
\hline \multicolumn{7}{|l|}{ Grade } \\
\hline- & Neg & Neg & Neg & Neg & Neg & Neg \\
\hline+- & 5 & 5 & 5 & 5 & NA & NA \\
\hline $1+$ & 10 & 10 & 15 & 15 & 10 & $10-20$ \\
\hline $2+$ & 50 & 50 & 50 & 40 & 30 & $40-60$ \\
\hline $3+$ & 100 & 100 & 150 & $\geq 80$ & 80 & $80-100$ \\
\hline $4+$ & NA & NA & NA & 160 & NA & $>150$ \\
\hline \multicolumn{7}{|l|}{ Bilirubin } \\
\hline Unit & $\mathrm{mg} / \mathrm{dL}$ & $\mathrm{mg} / \mathrm{dL}$ & $\mathrm{mg} / \mathrm{dL}$ & $\mathrm{mg} / \mathrm{dL}$ & $\mathrm{mg} / \mathrm{dL}$ & $\mathrm{mg} / \mathrm{dL}$ \\
\hline \multicolumn{7}{|l|}{ Grade } \\
\hline- & & & Neg & Neg & NA & NA \\
\hline+- & NA & NA & NA & NA & NA & NA \\
\hline $1+$ & 0.5 & 0.5 & 1 & Small & 0.5 & $0.5-1.0$ \\
\hline $2+$ & 1 & 1 & 3 & Moderate & 1 & $2.0-4.0$ \\
\hline $3+$ & 3 & 3 & 6 & Large & 2 & $6.0-10.0$ \\
\hline $4+$ & NA & NA & NA & NA & NA & $>10$ \\
\hline \multicolumn{7}{|c|}{ Urobilinogen } \\
\hline Unit & $\mathrm{mg} / \mathrm{dL}$ & $\mathrm{mg} / \mathrm{dL}$ & $\mathrm{mg} / \mathrm{dL}$ & $\mathrm{mg} / \mathrm{dL}$ & $\mathrm{mg} / \mathrm{dL}$ & $\mathrm{mg} / \mathrm{dL}$ \\
\hline \multicolumn{7}{|l|}{ Grade } \\
\hline- & NA & NA & Normal & 0.2 & NA & NA \\
\hline+- & 0.1 & NA & 1 & 1 & NA & Normal \\
\hline $1+$ & 1 & 1 & 4 & 2 & 2 & $2-3$ \\
\hline $2+$ & 4 & 4 & 8 & 4 & 4 & $4-6$ \\
\hline $3+$ & 8 & 8 & 12 & $>8$ & 8 & $8-12$ \\
\hline $4+$ & 12 & 12 & NA & NA & 25 & $>12$ \\
\hline
\end{tabular}

The instruments were from the following companies: YD (YD Diagnostics, Yongin, Korea), SD (Standard Diagnostics, Seoul, Korea), Roche (Roche Diagnostics, Mannheim, Germany), Siemens (Siemens Healthcare, Erlangen, Germany), Sysmex (Sysmex Co., Kobe, Japan), and Arkray (Arkray Inc., Kyoto, Japan).

Abbreviations: RBC, red blood cell; Neg, negative; NA, not available; WBC, white blood cell. 


\section{재료 및 방법}

\section{1. 사용 검체}

본 연구에 사용되는 물질은 인체에서 유래한 정상 소변 및 비정
상 소변과, 요화학검사를 위해 시판되는 정도관리물질을 사용하 였다. 소변검사에서 정상 및 비정상 결과를 보이는 환자들의 검체 를 모아서 정상 및 비정상 소변을 제조하였다. 정도관리물질로는 Uritrol level 1, 2, 3, 4 (QC1, QC2, QC3, QC4; YD Diagnostics,

Table 2. Analysis of the matrix effect of four QC materials

\begin{tabular}{|c|c|c|c|c|c|c|c|c|c|}
\hline \multirow{2}{*}{ QC materials } & \multirow{2}{*}{ Test name } & \multirow{2}{*}{ Grade } & \multicolumn{7}{|c|}{ Company } \\
\hline & & & YD & SD & Roche & Siemens & Sysmex & Arkray & Total \\
\hline \multirow[t]{8}{*}{ Aution Check level $2(\mathrm{~N}=20)$} & $\mathrm{pH}$ & 7.5 & 19 & 0 & 0 & 0 & 3 & 0 & 22 \\
\hline & & 8 & 0 & 7 & 9 & 0 & 15 & 20 & 51 \\
\hline & & 8.5 & 0 & 12 & 0 & 19 & 1 & 0 & 32 \\
\hline & & 9 & 0 & 0 & 11 & 0 & 1 & 0 & 12 \\
\hline & Specific gravity & 1 & 0 & 0 & 0 & 0 & 0 & 20 & 20 \\
\hline & & 1.005 & 0 & 0 & 0 & 0 & 1 & 0 & 1 \\
\hline & & 1.01 & 1 & 19 & 0 & 15 & 19 & 0 & 54 \\
\hline & & 1.015 & 19 & 0 & 20 & 3 & 0 & 0 & 42 \\
\hline \multirow[t]{8}{*}{ Liquichek level $2(\mathrm{~N}=20)$} & Urobilinogen & $1+$ & 0 & 0 & 0 & 0 & 0 & 20 & 20 \\
\hline & & $2+$ & 0 & 0 & 20 & 0 & 0 & 0 & 20 \\
\hline & & $3+$ & 13 & 17 & 0 & 19 & 16 & 0 & 65 \\
\hline & & $4+$ & 7 & 1 & 0 & 0 & 3 & 0 & 11 \\
\hline & Specific gravity & 1.015 & 0 & 0 & 0 & 5 & 0 & 0 & 5 \\
\hline & & 1.02 & 18 & 17 & 20 & 14 & 0 & 20 & 89 \\
\hline & & 1.025 & 2 & 1 & 0 & 0 & 0 & 0 & 3 \\
\hline & & 1.03 & 0 & 0 & 0 & 0 & 19 & 0 & 19 \\
\hline \multirow[t]{13}{*}{ UroColor Control $2(\mathrm{~N}=20)$} & Bilirubin & $\mathrm{N}$ & 0 & 0 & 0 & 0 & 0 & 20 & 20 \\
\hline & & $1+$ & 0 & 0 & 4 & 0 & 0 & 0 & 4 \\
\hline & & $2+$ & 0 & 8 & 16 & 4 & 4 & 0 & 32 \\
\hline & & $3+$ & 20 & 12 & 0 & 0 & 16 & 0 & 48 \\
\hline & $\mathrm{pH}$ & 8 & 20 & 18 & 19 & 0 & 3 & 0 & 60 \\
\hline & & 8.5 & 0 & 2 & 0 & 1 & 4 & 20 & 27 \\
\hline & & 9 & 0 & 0 & 1 & 0 & 13 & 0 & 14 \\
\hline & & 9.5 & 0 & 0 & 0 & 3 & 0 & 0 & 3 \\
\hline & Specific gravity & 1.005 & 20 & 7 & 20 & 0 & 0 & Low & 47 \\
\hline & & 1.01 & 0 & 13 & 0 & 2 & 0 & Low & 15 \\
\hline & & 1.015 & 0 & 0 & 0 & 2 & 3 & Low & 5 \\
\hline & & 1.02 & 0 & 0 & 0 & 0 & 8 & Low & 8 \\
\hline & & 1.025 & 0 & 0 & 0 & 0 & 8 & Low & 8 \\
\hline \multirow[t]{5}{*}{ UC-Control $2(\mathrm{~N}=10)$} & Bilirubin & $\mathrm{N}$ & 0 & 10 & 0 & 0 & 6 & 0 & 16 \\
\hline & & $\operatorname{tr}$ & 0 & 0 & 0 & 0 & 0 & 0 & 0 \\
\hline & & $1+$ & 0 & 0 & 0 & 0 & 0 & 0 & 0 \\
\hline & & $2+$ & 0 & 0 & 0 & 0 & 3 & 0 & 3 \\
\hline & & $3+$ & 10 & 0 & 10 & 10 & 1 & 10 & 41 \\
\hline
\end{tabular}


Table 2. Continued

\begin{tabular}{|c|c|c|c|c|c|c|c|c|c|}
\hline \multirow{2}{*}{ QC materials } & \multirow{2}{*}{ Test name } & \multirow{2}{*}{ Grade } & \multicolumn{7}{|c|}{ Company } \\
\hline & & & YD & SD & Roche & Siemens & Sysmex & Arkray & Total \\
\hline \multirow[t]{7}{*}{ UC-Control $2(\mathrm{~N}=10)$} & Ketone & $1+$ & 0 & 0 & 0 & 10 & 0 & 0 & 10 \\
\hline & & $2+$ & 10 & 10 & 0 & 0 & 0 & 0 & 20 \\
\hline & & $3+$ & 0 & 0 & 10 & 0 & 10 & 10 & 30 \\
\hline & Specific gravity & 1.015 & 0 & 10 & 0 & 4 & 0 & 0 & 14 \\
\hline & & 1.02 & 1 & 0 & 0 & 6 & 0 & 0 & 7 \\
\hline & & 1.025 & 9 & 0 & 10 & 0 & 8 & 10 & 37 \\
\hline & & 1.03 & 0 & 0 & 0 & 0 & 2 & 0 & 2 \\
\hline
\end{tabular}

The instruments were from the following companies: YD (YD Diagnostics, Yongin, Korea), SD (Standard Diagnostics, Seoul, Korea), Roche (Roche Diagnostics, Mannheim, Germany), Siemens (Siemens Healthcare, Erlangen, Germany), Sysmex (Sysmex Co., Kobe, Japan), and Arkray (Arkray Inc., Kyoto, Japan). The results showing error message were not included. The results that differed more than 1 grade from the most frequent results were indicated in bold font. Abbreviation: QC, quality control.

Youngin, Korea)과 Aution Check Plus level 2 (Arkray Inc., Kyoto, Japan), Liquichek Urinalysis Control level 2 (BioRad Laboratories, Hercules, CA, USA), UroColor Control level 2 (Standard Diagnostics [SD], Seoul, Korea) 및 UCControl level 2 (Sysmex Co., Kobe, Japan)를 사용하였다. YD 의 $\mathrm{QC1}, \mathrm{QC2}, \mathrm{QC3}$ 및 $\mathrm{QC4}$ 물질은 1 차 검사와 2차 검사에 각각 다른 제조번호의 물질이 사용되었다.

\section{2. 사용 장비}

대상상비를 선정하기 위하여 2018년도 대한임상검사정도 관리협회 신빙도조사 결과를 참조하였으며, 회사별로 가장 많 이 사용하고 있는 모델을 대상으로 하였다. 따라서 Urinscan Super Plus (YD Diagnostics), Aution Max AX-4030 (Arkray Inc.), UroMeter 720 Pro (Standard Diagnostics), URISYS 2400 (Roche Diagnostics, Mannheim, Germany), Clinitek Adventus (Siemens, Erlangen, Germany) 및 UC-3500 (Sysmex Co.) 등 6종의 요화학검사 장비 및 시약을 사용하였다.

\section{3. 기질효과 분석}

보다 정확한 분석을 위하여 1 차 선별검사 및 2차 확인검사로 나 누어 진행하였다. 1 차 검사에서는 정상 및 비정상의 2 종의 소변 및 $\mathrm{YD}$ 이외의 정도관리물질 4종을 대상으로 30 분 내에 각 20 회 1 차 요화학검사를 시행하였다. 2차 확인검사에서는 Siemens사를 제 외한 5 개사 장비로 정상 및 비정상뇨와 YD Uritrol 4종의 검체를 동일 장소에서 각 40 회 요화학검사를 시행하였다. 검체의 변성을 막기 위하여 각 검체를 40 개로 분주하여 1 시간 이내에 검사하였다.

\section{4. 기질효과 판정}

YD 정도관리물질에 대한 기질효과 여부의 판정을 위하여 각 회사 장비별로 $70 \%$ 이상의 일치를 보이는 결과를 중심으로 \pm 1 grade 범위를 정답으로 하였다. 만약 $70 \%$ 이상 일치하는 결과가 없으면 YD 장비의 국내 보급율이 $39.8 \%$ 로 가장 빈번하여 YD 장 비를 중심으로 \pm 1 grade 범위를 정답으로 하였다.

결과 판정을 위하여 각 제조사의 판정기준을 조사하여 Table 1 에 제시하였다. 요잠혈검사에서 Roche사는 trace 판정기준이 타 사의 $1+$ 와 동일하였다. Sysmex, Arkray사는 보고단위가 $\mathrm{mg} / \mathrm{dL}$ 를 사용하였고 Siemens는 별도의 독립된 판정기준을 가져서 $\mathrm{YD}$, $\mathrm{SD}$, Roche사와 직접적인 비교를 하기 어려웠다. 백혈구검사에서 도 Siemens는 별도의 독립된 판정기준을 사용하였고 나머지 5 개 사는 유사하였다. Nitrite 검사는 Sysmex 및 Arkray가 2단계의 양성 판정기준을 사용하였고 나머지 4 개사는 1 단계의 양성기준만 사용하였다. Protein 검사에서 Roche사는 trace 및 1+ 판정기준 이 타사의 $1+$ 및 2+와 동일하였다. Glucose 검사는 YD 및 SD사 의 trace 및 $1+$ 판정기준이 다른 4 개사의 $1+$ 및 2+와 동일하였다. Ketone 검사는 6개사 모두 판정기준이 유사하였다. Bilirubin 검 사는 YD, SD, Sysmex사의 2+ 및 3+가 Roche 및 Arkray사의 1+ 및 2+에 해당하였으며 Siemens는 별도의 독립된 판정기준을 사 용하였다. Urobilinogen 검사는 Roche사의 trace, $1+$ 가 YD 및 $\mathrm{SD}$ 사의 2+ 및 3+에 해당하였다. 따라서 시약에 따른 기질효과 여 부를 판정하기 위해서는 시약 간의 판정기준 차이를 감안하여 시 행하였다. 


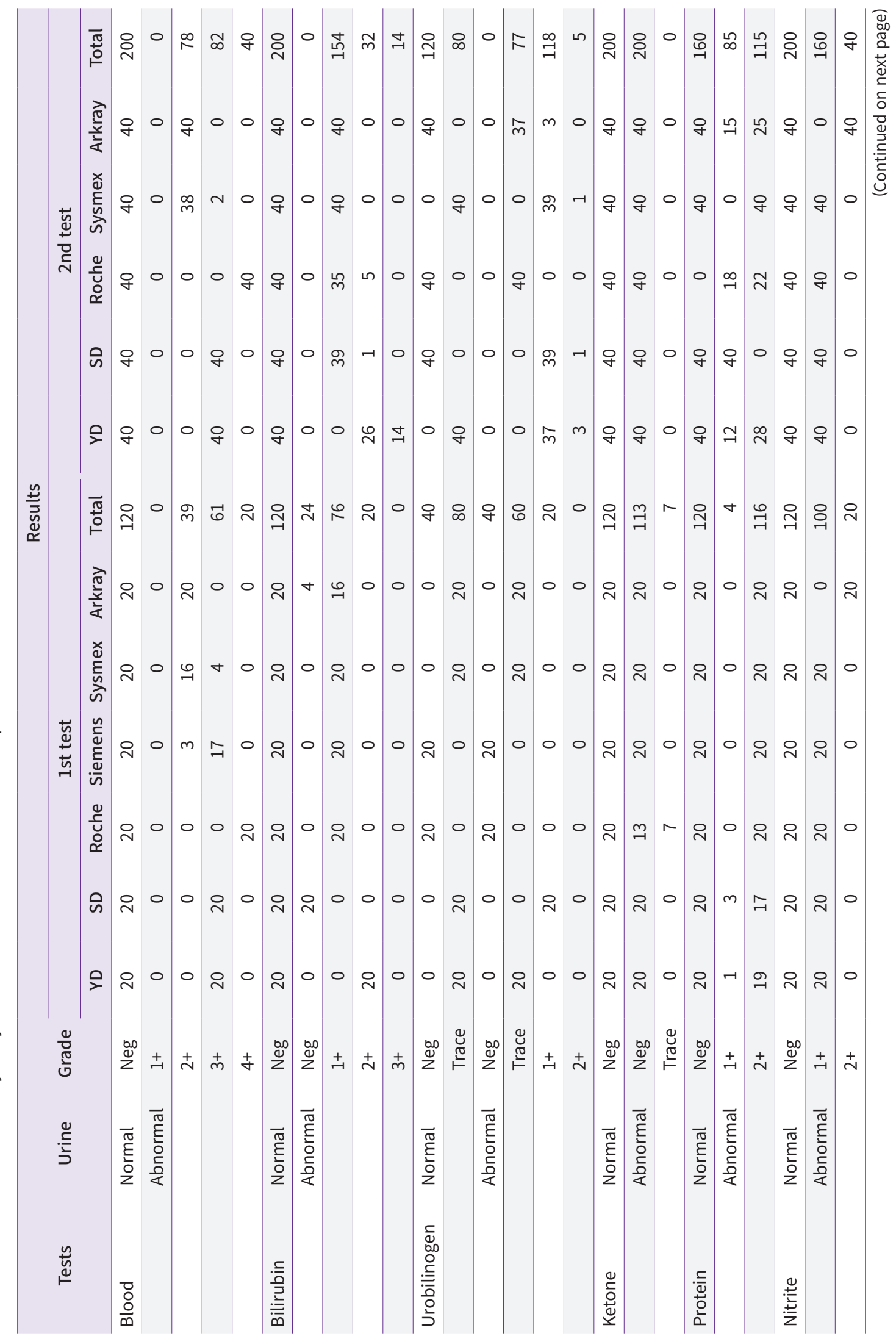


胥

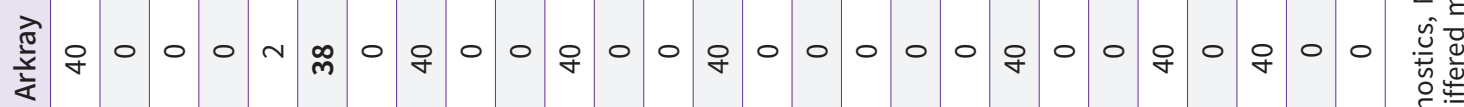

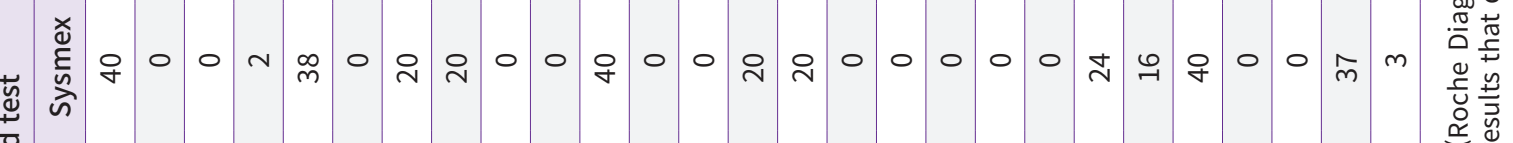



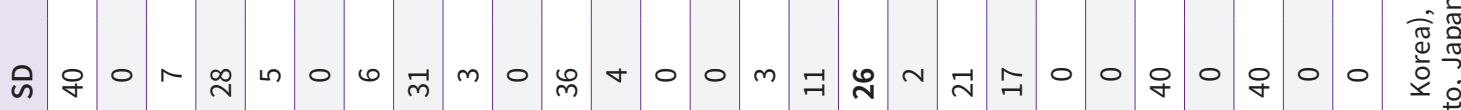

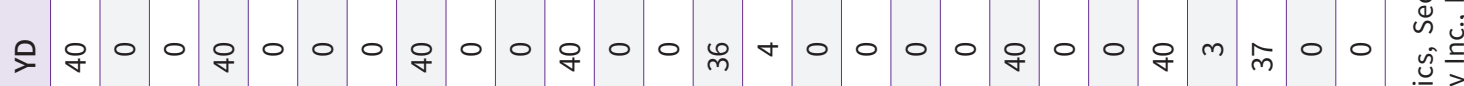

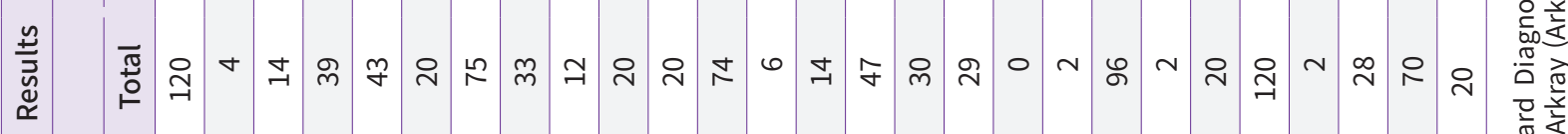

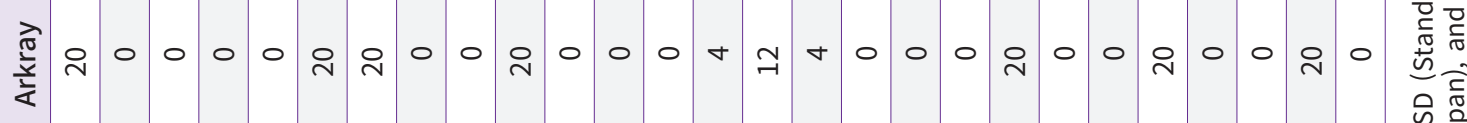

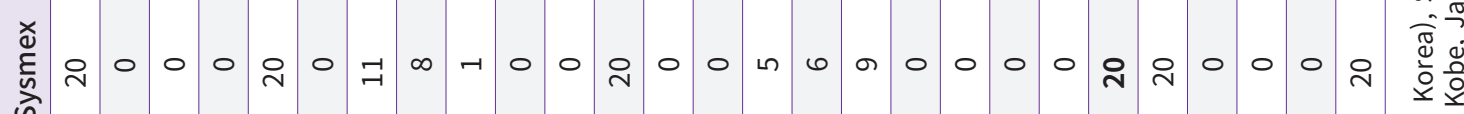
感 苟

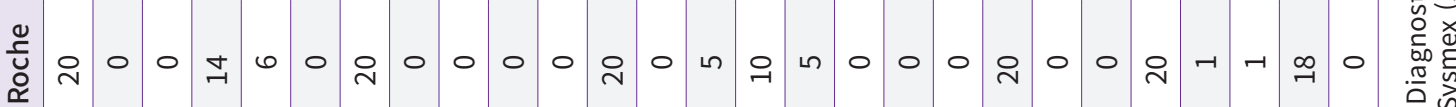
uิ

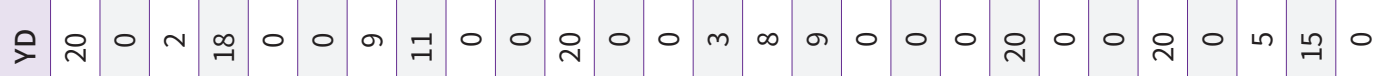

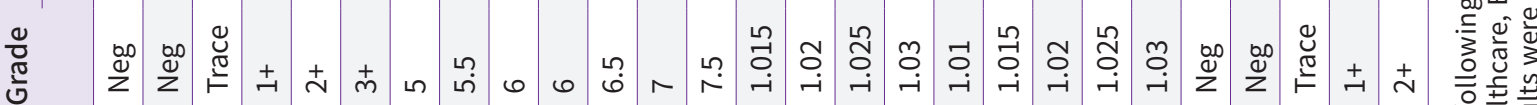




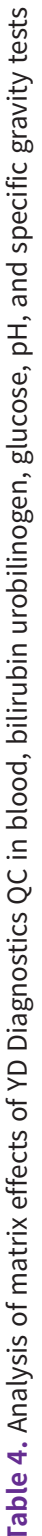

胥

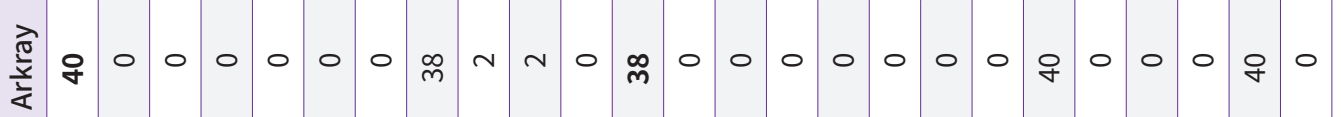

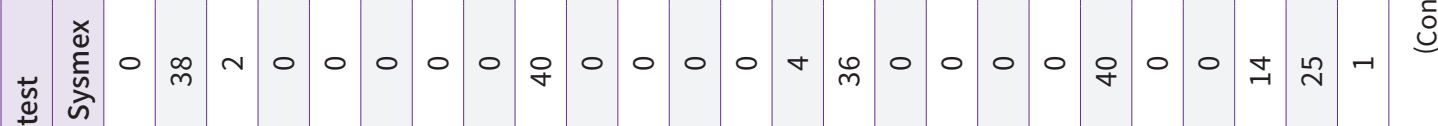

든



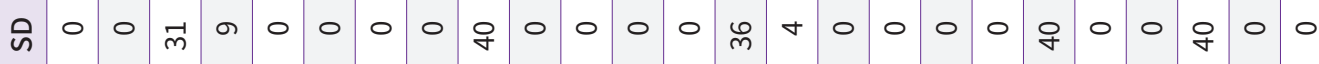



泀 $\rightarrow$ ป

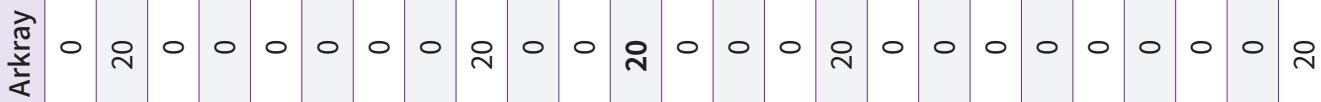

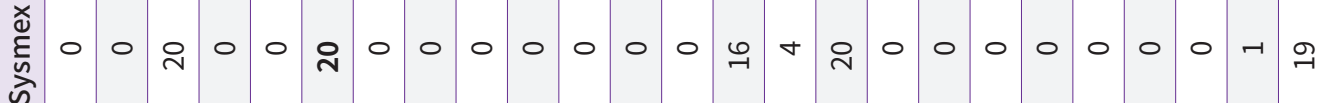



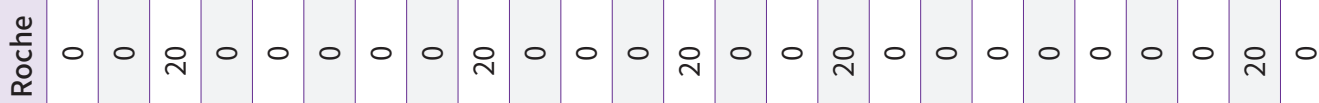

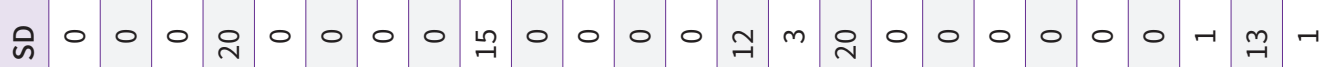

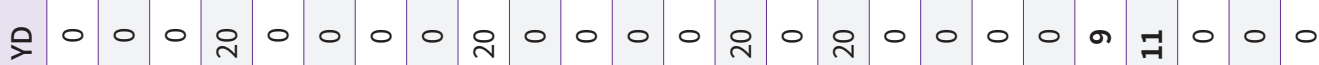



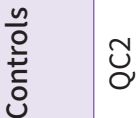

ঠ্ত

导

ปั

弚 


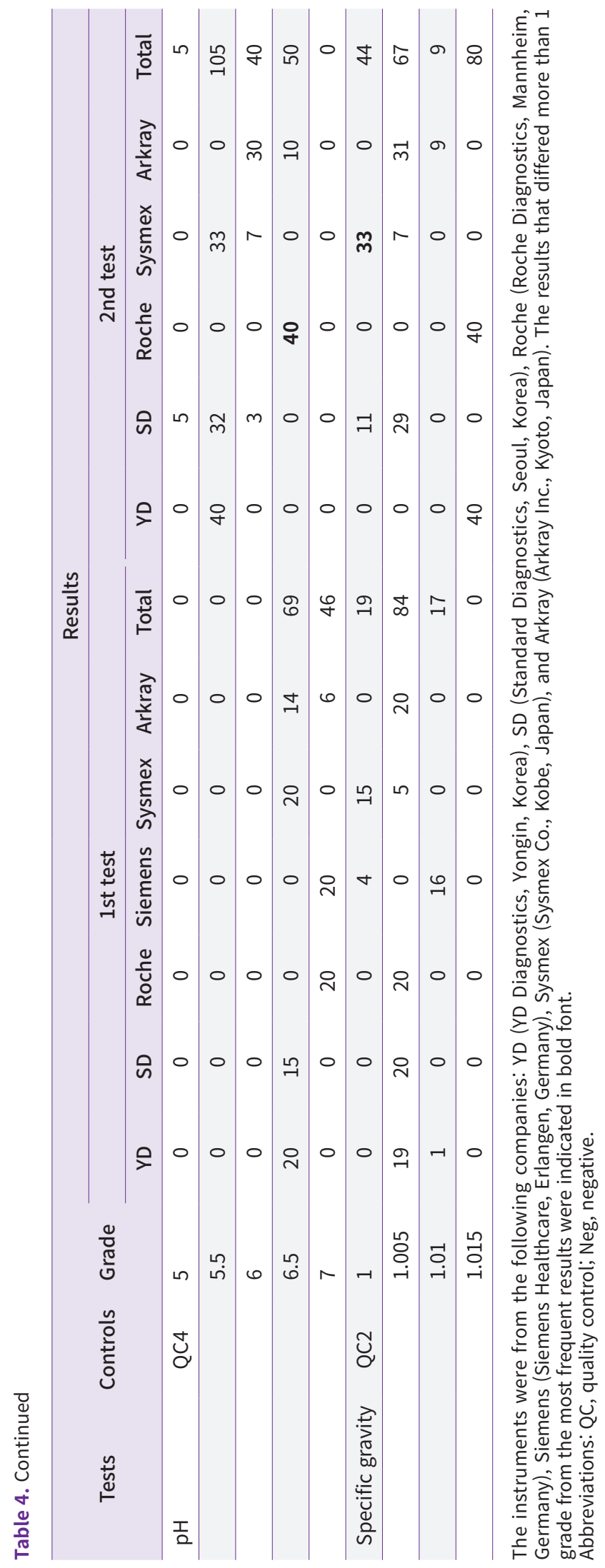

\section{결과}

\section{1. 정도관리물질에 따른 기질효과 분석}

다른 회사에서 시판되는 4 가지 정도관리물질에 대한 기질효과 를 분석한 결과는 Table 2에 제시하였다. Aution Check level 2에서 Roche 및 Arkray 시약은 $\mathrm{pH}$ 및 SG에 각각 기질효과를 나타냈다. Liquchek level 2에서 Arkray 및 Sysmex 시약은 urobilinogen 및 SG에 각각 기질효과를 나타냈다. SD Control 2 에서 Arkray 시약은 blood 및 SG에, Sysmex 시약은 pH 및 SG 에 각각 기질효과를 나타냈다. Sysmex Control 2에서 SD 시약 은 bilirubin 및 SG에, Sysmex 시약은 bilirubin에, Siemens 시 약은 urobilinogen에 각각 기질효과를 나타냈다. 상기 결과에서 모든 정도관리물질이 일부 항목에서 기질효과를 나타냈다.

\section{2. 정상 및 비정상뇨에 대한 결과}

요화학 장비 6종을 사용하여 정상 및 비정상뇨에 대한 분석결 과는 Table 3에 제시하였다. Blood, bilirubin, urobilinogen, ketone, protein, nitrite 및 leukocyte에서는 장비 간 차이가 나 타나지 않았다. Glucose 검사에서는 SD 시약이 1차 검사에서 1 단계 낮은 결과를 나타냈고, Arkray 시약이 1단계 높은 결과를 나 타냈다. SG 검사에서 Sysmex 시약이 1차 검사에서, SD 시약은 2 차 검사에서 각각 1 단계 높은 결과를 나타냈다.

\section{YD 정도관리물질에 대한 기질효과 분석}

YD 정도관리물질 4종류에 대한 장비별 기질효과 분석을 시행 하였고, 환자들의 정상뇨와 비정상뇨를 대상으로 환자 결과에 실 질적인 영향을 미치는지 확인하였다. 총 10종의 요화학검사항목 에서 blood, bilirubin, urobilinogen, glucose, pH 및 SG 등 6 종의 검사에서 기질효과가 관찰되었다(Table 4). 그 외 ketone, protein, nitrite 및 백혈구검사에서는 정도관리물질에서 기질효 과가 나타나지 않았다.

먼저 blood에 대한 기질효과 분석결과 Arkray 제품은 2차 실험 의 QC2 물질에 대해 기질효과를 나타냈으나 환자 검체에서는 타 제품과 동일한 결과를 나타냈다. Roche 제품도 QC2 물질에 대해 기질효과를 나타냈으나 판정기준이 달라 기질효과로 간주할 수 없 었다. 나머지 QC1, QC3, QC4에 대해서는 5개 시약에서 기질효과 가 관찰되지 않았다.

Bilirubin에 대한 기질효과 분석결과 Sysmex 시약은 1차 실험 에서 QC4 검체에 대해 기질효과를 나타냈으나, 환자 검체에서는 타 제품과 동일한 결과를 나타냈다. 나머지 QC1, QC2, QC3에 대 해서는 5 개 시약에서 기질효과가 관찰되지 않았다.

Urobilinogen에 대한 기질효과 분석결과 Arkray 시약은 1차 
및 2차 실험에서 QC4 검체에 대해 기질효과를 나타냈으나, 환자 검체에서는 타 제품과 동일한 결과를 나타냈다. 나머지 QC1, QC2, $\mathrm{QC} 3$ 에 대해서는 5개 시약에서 기질효과가 관찰되지 않았다.

Glucose 검사에 대한 기질효과 분석결과 YD 시약은 1차 QC4 및 2차 QC2 정도관리물질에서 기질효과를 나타냈으며, 인체 유래 비정상 소변에서는 다른 시약과 동일한 결과를 나타냈다.

$\mathrm{pH}$ 검사에 대한 기질효과 분석결과 Roche 시약은 2차 QC4 정 도관리물질에서 기질효과를 나타냈으며, 인체 유래 비정상 소변에 서는 다른 시약과 동일한 결과를 나타냈다.

비중검사에 대한 기질효과 분석결과 Sysmex 시약은 2차 QC2 정도관리물질에서 기질효과를 나타냈으며, 인체 유래 비정상 소변 에서 1,2 차 모두 다른 시약보다 1 단계 높은 결과를 나타냈다.

\section{고찰}

요화학검사 신빙도조사는 전국적으로 약 1,500 여 기관이 참여하 여 연 3회에 걸쳐 시행되고 있다[1,2]. 참여기관의 결과에 대한 판 정은 보고한 기관에서 $80 \%$ 이상의 일치를 보이는 결과로 선정한 다. 따라서 보고한 기관 간의 결과의 일치도가 중요하지만 각 기관 마다 사용하는 장비가 달라서 장비에 의한 결과차이가 나타날 수 있다.

장비에 의한 결과차이는 동종 기기를 사용하는 군을 기준으로 판정하면 표준화를 할 수 있으나 사용하는 정도관리물질에 의해서 도 결과차이를 보일 수 있다. 즉 기질효과는 분석물질 외에 검체에 의하여 측정값에 영향을 미치는 경우이다[3].

요화학검사의 신빙도조사를 위하여 국내 시약회사에서 액 상으로 제조되는 정도관리물질을 사용하고 있다. 이 물질은 phosphate buffered saline에 요화학검사를 위한 첨가물을 혼 합하여 정도관리물질로 사용하고 있다. 따라서 기질효과가 발생할 가능성이 높아서 이에 대한 연구를 시행하게 되었다.

정확한 기질효과 판정을 위해서는 기질효과를 보이지 않는 물 질과 표준법(primary reference measurement procedure)이 필요하다[3]. 이를 위해 본 연구에서는 인체 유래 정상 소변과 비 정상 소변을 사용하였고, 각 회사 장비별로 $70 \%$ 이상의 일치를 보이는 결과를 표준법에 의한 결과로 사용하였다.

다른 회사에서 시판되는 정도관리물질에 대한 기질효과를 분 석하기 위하여 4 가지 정도관리물질을 사용하였다. 정상범위를 보이는 정도관리물질은 기질효과가 잘 나타나지 않아 비정상결 과를 보이는 정도관리물질을 사용하였다. Arkray사의 Aution Check Plus는 Quantimetrix사(Redondo Beach, CA, USA)의 Dropper Plus 제품이다. 인체 유래 소변을 기반으로 한 액상으로 제조되었으며 미생물 증식을 억제하기 위한 보존제가 함유되었다.
개봉 시 실온에서 1 개월 사용 가능하고 냉장보관 시 18 개월간 안 전하다. Bio-Rad사의 Liquichek Urinalysis Control도 보존제 를 함유한 인체 유래 소변을 기반으로 한 액상으로 제조되었다. 보 존 및 사용기한은 Dropper Plus와 유사하다. Sysmex사의 UCControl도 보존제를 함유한 인체 유래 소변을 기반으로 한 액상으 로 제조되었다. SD사의 UroColor Control은 양성 및 음성을 보 이는 시험지봉으로 제조되었으며, 일정량의 증류수에 넣어 용출시 킨 다음 정도관리물질로 사용한다.

본 연구에서 4 개 회사의 정도관리물질 모두 일부 검사항목에서 기질효과를 나타냈다. $\mathrm{pH}$ 검사항목에서는 대부분의 요화학 장비 에서 $6.5,7,8,9$ 로 보고하여 Roche사의 결과는 장비 자체에서는 1 단계만 차이 나지만 신빙도조사의 보고단위 양식이 0.5 단위로 분류되어 기질효과가 있는 것으로 판정하였다.

$\mathrm{YD}$ 이외의 정도관리물질에서도 기질효과가 관찰되고, 2가지 농 도만 시판하므로 다양한 농도가 요구되는 신빙도조사에서는 4 가 지 농도를 생산하는 $\mathrm{YD}$ 의 정도관리물질을 그대로 사용하는 것이 바람직하였다.

$\mathrm{YD}$ 의 정도관리물질 $\mathrm{QC1}-\mathrm{QC} 4$ 에 대한 기질효과 분석을 정도 관리 물질별로 요약하면 다음과 같다. QC2 검체에 대해 blood (Arkray), glucose (YD), 요비중(Sysmex) 3개 항목, QC4 검체 에 대해 bilirubin (Sysmex), urobilinogen (Arkray), glucose (YD), $\mathrm{pH}$ (Roche) 4 개 항목에서 각각 기질효과가 관찰되었다. YD 의 $\mathrm{QC1}$ 및 $\mathrm{QC3}$ 검체는 기질효과가 관찰되지 않았는데, $\mathrm{QC1}$ 검 체는 정상범위에 분포하는 결과가 많았다.

국내에서 제조되는 YD와 SD사의 정도관리물질은 소변 기반이 아니고 각각 생리식염수와 증류수를 기반으로 하고 있다. 반면, Liquichek, Aution Check, UC-Control 등은 소변 기반으로 제 조되었다. 소변 기반으로 제조되어 기질효과는 발생하지 않아야 하지만 보존제 및 첨가제를 함유하여 기질효과의 발생을 완전히 배제할 수는 없다. 또한 세계적으로도 요화학검사에 대한 기질효 과에 대한 연구를 찾아보기 어렵다[4]. 따라서 향후 이 분야에 대 한 관심과 추가적인 연구가 필요한 실정이다.

본 연구에서는 현재 시판되고 있는 정도관리물질 4종에 대한 기 질효과를 분석하여 기질효과가 관찰됨을 확인하였다. 또한 $\mathrm{YD}$ 의 정도관리물질 4종에 대한 장비별 기질효과를 확인하였다. 즉 모 든 정도관리물질에서 기질효과가 발생하였다. 따라서 기질효과가 발생하지 않는 정도관리물질을 신빙도조사에 사용하는 것이 필요 하다. 이를 위해 인체 유래 소변을 사용하는 것이 가장 바람직하지 만, 실제로 수작업으로 제조하여 신빙도조사 물질로 사용하기에는 현실적으로 매우 어려운 실정이다. 따라서 현재 회사별로 시행되 고 있는 기관별 결과 판정기준을, 장비별 판정기준으로 세분화하 는 것이 바람직하였다. 


\section{감사의 글}

본 연구는 대한임상검사정도관리협회의 연구비 지원으로 수행

되었다(2019).

\section{REFERENCES}

1. Jeon CH, Lee AJ, Kim SG, Suh HS, Bae YC. Annual report on the external quality assessment scheme for urinalysis and faecal occult blood testing in Korea (2016). J Lab Med Qual Assur 2017;39:117-23.

2. Jeon CH, Lee AJ, Kim SG, Suh HS, Bae YC. Annual report on the external quality assessment scheme for urinalysis and fecal occult blood testing in Korea (2017). J Lab Med Qual Assur 2018;40:128-35.

3. Lasky FD, Kroll MH, Tholen DW. Evaluation of matrix effects; approved guideline: EP14-A2. 2nd ed. Wayne (PA): Clinical and Laboratory Standards Institute, 2005.

4. Taylor TP, Janech MG, Slate EH, Lewis EC, Arthur JM, Oates JC. Overcoming the effects of matrix interference in the measurement of urine protein analytes. Biomark Insights 2012;7:1-8. 